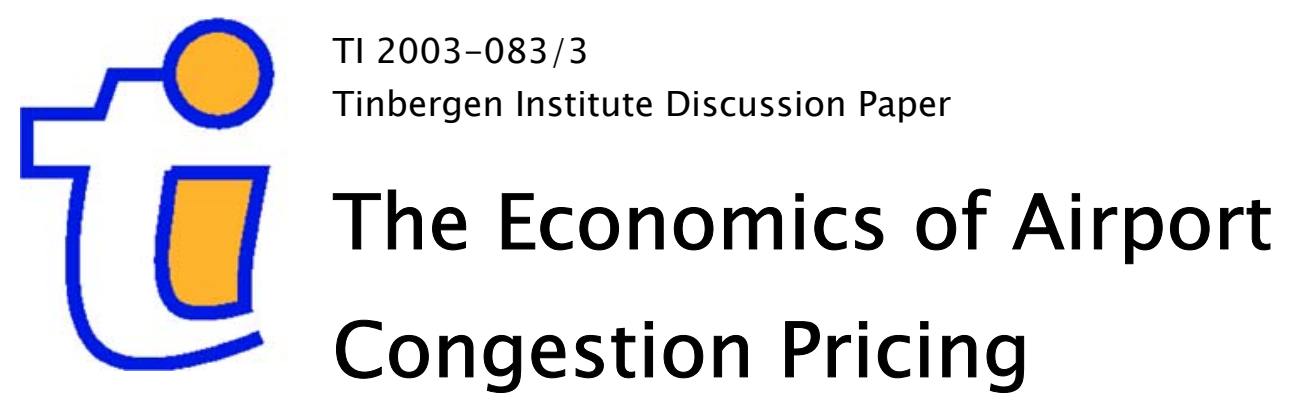

\author{
Eric Pels \\ Erik T. Verhoef:
}

Department of Spatial Economics, Faculty of Economics and Business Administration, Vrije Universiteit Amsterdam.

* Tinbergen Institute. 


\section{Tinbergen Institute}

The Tinbergen Institute is the institute for economic research of the Erasmus Universiteit Rotterdam, Universiteit van Amsterdam, and Vrije Universiteit Amsterdam.

Tinbergen Institute Amsterdam

Roetersstraat 31

1018 WB Amsterdam

The Netherlands

Tel.: $\quad+31(0) 205513500$

Fax: $\quad+31(0) 205513555$

Tinbergen Institute Rotterdam

Burg. Oudlaan 50

3062 PA Rotterdam

The Netherlands

Tel.: $\quad+31(0) 104088900$

Fax: $\quad+31(0) 104089031$

Please send questions and/or remarks of nonscientific nature to driessen@tinbergen.nl.

Most TI discussion papers can be downloaded at http://www.tinbergen.nl. 


\title{
The Economics of Airport Congestion Pricing ${ }^{1}$
}

\author{
Eric Pels \\ Erik T. Verhoef \\ Free University Amsterdam, Department of Spatial Economics \\ De Boelelaan 1105, 1081 HV Amsterdam, The Netherlands \\ Email: apels@feweb.vu.nl everhoef@feweb.vu.nl \\ telephone: $+31-20-4446049+31-20-4446094$ \\ fax: $+31-20-4446004$
}

\begin{abstract}
.
Conventional economic wisdom suggests that congestion pricing would be an appropriate response to cope with the growing congestion levels currently experienced at many airports. Several characteristics of aviation markets, however, may make naive congestion prices equal to the value of marginal travel delays a non-optimal response. This paper develops a model of airport pricing that captures a number of these features. The model in particular reflects (1) that airlines typically have market power and are engaged in oligopolistic competition at different sub-markets; (2) that part of external travel delays that aircraft impose are internal to an operator and hence should not be accounted for in congestion tolls; and (3) that different airports in an international network will typically not be regulated by the same authority. We present an analytical treatment for a simple two-node network and some numerical results to illustrate our findings. Some main conclusions are that second-best optimal tolls are typically lower than what would be suggested by congestion costs alone and may even be negative, and that cooperation between regulators need not be stable but that non-cooperation may lead to welfare losses also when compared to a no-tolling situation.
\end{abstract}

Keywords: congestion, market power, networks, airports, airlines

\footnotetext{
${ }^{1}$ The authors thank Jan Brueckner for excellent comments on an earlier draft. Any remaining errors or shortcomings are the authors' responsibility alone. This paper is an outflow of earlier research carried out for the research project MC-ICAM, funded by the European Commission (GRD1/2000/25475-SI2.316057). This financial support is gratefully acknowledged.
} 
Many airports face capacity problems. In the U.S., 25 airports are classified as "severely congested" by the Federal Aviation Administration (Daniel [10]), while also in Europe many airports face congestion problems (e.g. London Heathrow, Frankfurt and Amsterdam Schiphol). This raises the economic issue of how to allocate scarce runway capacity. In the U.S., this is usually done on a first-come first-served principle. When capacity is limited, arriving aircraft consequently cause delays (and thus costs) for other arriving aircraft. Only four US airports (Washington Ronald Reagan, New York LaGuardia, New York Kennedy and Chicago O'Hare) are slot-constrained; with slot trading between airlines allowed (see e.g. Starkie [15]). European airports are usually slot-constrained; slots are allocated by a slot coordinator. The slot-allocation mechanism at most airports is not based on economic principles. The users of capacity (airlines) may pay less than the marginal social cost (congestion costs are not paid, entry is deterred), and are not necessarily the (potential) users that attach the highest economic value to the capacity.

Like slot trading, also airport congestion pricing aims to allocate scarce capacity to those parties that attach the highest economic value to it. Congestion pricing in aviation is, however, a relatively under-explored option in the literature. Most studies of congestion pricing in transport networks concern road traffic, and therefore consider link-based tolls. However, for aviation - and other modes - it may often be nodes, rather than links between them, that form the bottlenecks. A question that naturally arises is whether insights from studies on link-based pricing in road networks are directly transferable to node-based pricing, especially under second-best circumstances where multiple market distortions exist simultaneously. It may in particular be expected that the nature of such other market distortions, additional to congestion externalities, are different at nodes than along links. Given the substantial and growing congestion at major airports and other transport hubs throughout the world, it seems relevant to investigate the implications for congestion pricing.

An important difference between congestion on roads and in aviation is that individual road users typically do not have market power, and can thus be assumed to take travel times as given. Airports, in contrast, and especially the more congested hubs, will often have spatial monopolistic power, while their primary user(s), airlines, will often compete under oligopolistic conditions. Moreover, especially when positive network externalities (or 
economies of density) induce these airlines to operate hub-and-spoke networks, with different airlines using different hubs, these oligopolies may be asymmetric. A substantial share of congestion costs may then not constitute external effects, but be internal instead. That is, the travel delays imposed by one service upon other services may often concern services of the same operator, who can be assumed to take these firm internal congestion effects into account when determining profit-maximizing prices and frequencies. These firm-internal congestion costs should then not be included in congestion taxes (Brueckner [5]).

A further implication of oligopolistic competition would be that another distortion, besides congestion, is likely to be present, namely that of strategic interaction between competitors, with the result of non-competitive pricing. Absent congestion, consumer prices may then exceed marginal costs because airlines have market power, implying that an economic argument for subsidization rather than taxation would exist. As pointed out by Buchanan [8] and Baumol and Oates [1] in the context of a polluting monopolistic firm, the implication for Pigouvian externality pricing is that the second-best optimal tax would have to be below the marginal external costs, and may even become negative. This would provide a second argument, in addition to the point raised by Brueckner [5], why optimal congestion charges at a hub would be below marginal external congestion costs (if straightforwardly defined as the value of a single service's marginal delay costs for all other services).

This paper aims to investigate such issues by developing a model that considers second-best congestion pricing for incoming and outgoing flights at airports. The second-best circumstances under which congestion tolls have to be set are those just mentioned. We consider a simple network with two nodes, where both airlines and passengers suffer from congestion at airports. Three types of interacting players are present in our model: a regulatory authority, airlines, and passengers; each having their own objective. Congestion tolls can be determined by a single regulator for all airports in the network, but also by "local" regulators of specific airports. Tax competition between local regulators then becomes an issue.

As stated, airport congestion pricing has received limited attention in the literature. Carlin and Park [9] estimated the external cost of a peak-period landing at LaGuardia was \$2000 (in 1969 \$); about twenty times the actual landing fee, although this number should not be interpreted as an equilibrium congestion toll. Oum and Zhang [13] examine the relation between congestion tolls and capacity costs, and find that when capacity investment is lumpy, the cost recovery theorem (which states that congestion toll revenues just cover amortized 
capacity (expansion) costs under constant returns to scale) no longer holds. Daniel $[10,11]$ combines stochastic queuing theory with a Vickrey-type bottleneck model. His simulation results show that congestion pricing causes a redistribution of flights over the day, where smaller aircraft may divert to other airports because they value their use less than the social cost of using the congested airport. Brueckner [5] analyzes airport congestion pricing when airlines are non-atomistic, and concludes that there may be only a limited or even no role for congestion pricing when the number of airlines using the node decreases, as the share of internalized congestion costs increases. Brueckner [6] extends the analysis of Brueckner [5] to a network setting, and finds that an airline specific toll equals the congestion damage caused by the airline, multiplied by a fraction given by one minus the airline's flight share.

This paper adds two complications to the set-up considered by Brueckner [6]. An important one is the explicit consideration of market power distortions and the effects on optimal congestion tolls. Another is that airports need not cooperate optimally to maximize joint welfare, but instead may engage in a form of tax competition in the pursuit of maximizing local rather than global welfare.

The structure of the paper is as follows. First, the notation and main assumptions are introduced in Section 2. Section 3 derives an analytical equilibrium and optimality results for a symmetric duopoly. Sections 4 presents numerical results for a symmetric and an asymmetric duopoly. Section 5 considers tax competition between regulators. Finally, Section 6 concludes.

\section{NOTATION AND ASSUMPTIONS}

In the model, we distinguish three different parties: an endogenous number of passengers, two airlines, and two airport authorities. Passengers wish to travel between a given city pair. To do so, the services of an airline $i$ are necessary. The two airlines, in turn, need the services of two airports $h$ for each service: an origin and a destination. Prices for the use of an airport may in reality be set by a profit maximizing airport operator or a welfare maximizing regulatory authority. Because we are concerned with (second-best) optimal airport prices, we will be considering a (public) regulatory authority alone. An extension of the model to four types of players (regulators, private airport operators, airlines and passengers) is considered as an interesting option for future work. 
For the general specification of the model, a number of assumptions are made, that will now first be presented.

Assumption 1. A passenger return trip involves one airline only. The inverse aggregate demand is linear in form:

$D\left(\sum_{i=1}^{2} q_{i}\right)=\alpha-\beta \sum_{i=1}^{2} q_{i}$

where $\alpha>0$ and $\beta>0 ; \alpha$ represents the maximum reservation price, $\beta$ is the demand sensitivity parameter, and $q_{i}$ is the number of passengers transported by airline $i$. We consider one city pair only, served by direct flights, and the unit of analysis is return trips.

Assumption 2. An airline's frequency (in both directions) is:

$$
f_{i}=\frac{1}{\lambda_{i}} q_{i}
$$

where $\lambda_{i}$ is the given product of the load factor and the seat capacity, and thus gives the number of passengers per flight. Congestion occurs at nodes only (i.e., not on links; "capacity in the air" or the capacity of the air traffic control system is abundant). The average time loss per passenger or per flight due to congestion at node $h, \phi_{h}$, is assumed to increase linearly in the total frequency at that node:

$\phi_{h}=\eta_{h} \sum_{i=1}^{2} f_{i}=\eta_{h} \sum_{i=1}^{2} \frac{1}{\lambda_{i}} q_{i}$

where $\eta_{h}$ is the slope of the congestion function. Note that arriving and departing movements need not contribute equally to, and suffer equally from congestion. However, as we only consider return markets, we do not have to make this distinction, and $\phi_{h}$ gives the sum of time losses during departure and arrival on the airport.

The congestion term (in time units) to be included in the passengers' and airlines' (generalized) cost functions is then:

$\phi_{i}=\sum_{h=1}^{2} \phi_{h}$

Multiplying this term by the passengers' value of time ( vot $\left._{p}\right)$ and the airlines' value of time $\left(v o t_{l}\right)$ yields the monetized congestion delay cost to passengers and airlines, respectively (vot is assumed equal between airlines). The passengers' value of time would typically purely 
reflect lost time. The airline's value of time may also include additional resource costs: vot $_{l}$ would capture expenditures on fuel, crew time, etc.

Assumption 3. The generalized costs for an airlines' service, as experienced by passengers, is characterized by a generalized user cost function $g_{i}\left(p_{i}, v o t_{p} \times \phi_{\mathrm{i}}\right)$ where $p_{i}$ is the fare. The generalized user cost function is linearly additive in form:

$g_{i}=p_{i}+\operatorname{vot}_{p} \times \phi_{i}$

Assumption 4. The airline's cost per (return) passenger, $c_{i}^{q}$, and per (return) flight, $c_{i}^{f}$, are constant. The congestion toll at node $h$ is denoted $t_{h}$ and is valid for one arrival and one departure. Total operating costs for airline $i$ are then:

$f_{i}\left(c_{i}^{f}+\sum_{h=1}^{2} t_{h}+\operatorname{vot}_{l} \phi_{i}\right)+c_{i}^{q} q_{i}-F_{i}$

which may be rewritten as:

$q_{i} \times\left[\frac{1}{\lambda_{i}}\left(c_{i}^{f}+\sum_{h=1}^{2} t_{h}+\operatorname{vot}_{l} \phi_{i}\right)+c_{i}^{q}\right]-F_{i}$

where $F_{i}$ is airline $i$ 's fixed cost.

Assumption 5. The airlines act as Cournot duopolists (i.e. they choose an optimal output (and frequency) taking the other airline's output as given). Airlines do not believe that by their actions, they can affect the regulator's tolls (i.e. regulators and airlines are playing a Stackelberg type game, the regulators being the leader). Passengers are pure price takers, who regard the airlines as pure substitutes, so that network equilibrium conditions can be represented as a Wardrop equilibrium with respect to generalized costs.

Although these assumptions may seem restrictive, many of these are quite common in the aviation economics literature. The functional form of the cost function used in this paper is similar to the one used by Brueckner and Spiller $[7]^{2}$. Combined with a linear demand curve, the "Brueckner-Spiller" model has been used regularly to analyze aviation networks. Despite the conceptual simplicity, recent trends in the aviation markets can easily be explained using this model; see e.g. Brueckner [4] for an analysis of airline alliances, and Pels et al. [14] for

\footnotetext{
${ }^{2}$ Brueckner and Spiller [7] do not include congestion in their cost function.
} 
an analysis of optimal airline networks ${ }^{3}$. It is not the objective of this paper to calculate exact tolls for existing airports, for which these assumptions would clearly be too restrictive. This paper aims to develop theoretical insights into the consequences of airport congestion pricing, for which these assumptions suffice.

\section{THE SYMMETRIC DUOPOLY EQUILIBRIUM: ANALYTICAL SOLUTION}

With these assumptions, we can now derive some analytical results. There are three types of players in the model, passengers, airlines and regulatory authorities, each with their own maximization problem. The model is solved in three steps. First, a passenger demand function for network operator $i$ is determined. Then, using this demand function, the airline problem is specified, and the associated profit maximizing optimality conditions are derived. Finally, the regulator's problem is solved, again using the passenger demand function, and also using the operator optimality conditions as restrictions.

To determine the equilibrium, we focus in this section on a simple symmetric network, with two identical airports and two identical airlines offering services in one (direct) market only. Although these symmetry assumptions are not necessary to determine the equilibrium analytically, it greatly reduces the notation and enhances transparency. The assumption of symmetric airlines is relaxed in a numerical exercise below.

In this network, optimal congestion tolls are assumed to be the same for both airports, to reflect symmetry, but one of the two tolls could be set equal to zero without loss of generality. Moreover, the congestion toll cannot be distinguished from a subsidy necessary to counter the market-power effect. Hence, only a single toll $t$ appears in the airline cost functions. But because both airports charge this toll, the airline pays it twice for each return flight. In more complicated networks, airline-market specific subsidies and airport specific congestion tolls will typically be necessary to achieve optimal welfare.

\section{The passenger optimization problem}

The marginal passenger's maximum willingness to pay for airline $i$, including monetized time costs, is given by equation (1), while each passenger's generalized user cost for the use of operator $i$ are given by $g_{i, j}(\cdot)$ defined in equation (5). Intra-marginal passengers' net benefits

\footnotetext{
${ }^{3}$ See Brueckner [4] for additional references.
} 
are determined according to the familiar Marshallian surplus. According to Wardrop's equilibrium conditions, marginal benefits are equal to the generalized costs in equilibrium (or marginal net benefits are zero) for both airlines, so that $D(.)=.g_{i}(.) \forall i$ in equilibrium, while the generalized costs of an unused airline could not be lower than $D(.$.$) and would typically be$ higher. ${ }^{4}$ Because operators incur costs for a service also when $q_{i, j}=0$ (see (6)), an unused airline will however not survive in our model, and this possibility will be discarded. By assumption, demand and generalized cost functions are linear, so that the equilibrium condition for both airlines in the simple network implies the following fares:

$$
\begin{aligned}
& p_{1}=\alpha-\beta\left(q_{1}+q_{2}\right)-2 \eta_{h} \operatorname{vot}_{p} \frac{q_{1}+q_{2}}{\lambda} \\
& p_{2}=\alpha-\beta\left(q_{1}+q_{2}\right)-2 \eta_{h} \operatorname{vot}_{p} \frac{q_{1}+q_{2}}{\lambda}
\end{aligned}
$$

The third RHS-term is multiplied by 2 because congestion is experienced at both airports. This operator specific inverse demand curve incorporates passengers' optimizing behavior, and is used in the next step to maximize operator profits. Note that the arguments of this inverse demand function include the quantities sold by competing airline, and that the fares must be equal in an interior (symmetric) equilibrium.

\section{The airline maximization problem}

As stated in assumption 5, we assume Cournot behavior in modeling airline competition. This is motivated by earlier (empirical) research. ${ }^{5}$ In a Cournot oligopoly, excess profits can be made when the number of suppliers is finite. The current financial problems of many airlines do not mean that Cournot oligopoly modeling would not be appropriate for this sector. High fixed costs may contribute to financial problems, also under Cournot competition.

Thus, the operators in this model maximize profits with respect to $q_{i}$, taking the competitors quantities as given (note that the assumption of a fixed passenger load implies

\footnotetext{
${ }^{4}$ Wardrop's first principle (Wardrop [16]) is commonly used in the road pricing literature to characterize network equilibrium conditions. In short, it states that in equilibrium, the generalized user cost of all used alternatives (e.g., routes) for a given market (e.g., as defined by origin-destination pairs) must be equalized while no lower cost alternatives can be available (otherwise people would switch alternatives). With elastic demand, the resulting equilibrium average generalized user cost must in addition be equal to the marginal benefits of travel (if, for instance, the marginal benefits would be higher, additional passengers would enter the network).

${ }^{5}$ For instance, in an empirical analysis of Chicago-based airline routes involving American Airlines and United Airlines, Oum et al. [12] conclude that "the overall results indicate that theduopolists' conduct may be described as somewhere between Bertrand and Cournot behavior, but much closer to Cournot, in the majority of the sample observations". Brander and Zhang [2], using similar data, find "strong evidence ... against the highly competitive Bertrand hypothesis". Brander and Zhang [2] findCournot behavior plausible for the markets under consideration (Chicago-based routes where American Airlines and United Airlines together have a market share exceeding 75\%). Based on these observations, we assume Cournot competition.
} 
that maximization with respect to frequencies independent of passenger numbers is neither possible nor necessary). In general, the maximization problem for operator $i(i=1,2)$ is:

$$
\max _{\mathrm{q}_{\mathrm{i}}} \pi_{\mathrm{i}}=\left[\alpha-\beta\left(q_{1}+q_{2}\right)-2 \operatorname{vot}_{p} \eta_{h} \frac{q_{1}+q_{2}}{\lambda}\right] q_{i}-q_{i}\left[\frac{c^{f}+2 t+2 v o t_{l} \eta_{h} \frac{q_{1}+q_{2}}{\lambda}}{\lambda}+c^{q}\right]-F
$$

The first-order necessary conditions for $i=(1,2)$ are:

$$
\begin{aligned}
& \alpha-\beta\left(q_{1}+q_{2}\right)-2 \operatorname{vot}_{p} \eta_{h} \frac{q_{1}+q_{2}}{\lambda}-q_{i}\left(\beta+\frac{2 v o t_{p} \eta_{h}}{\lambda}\right)- \\
& {\left[\frac{c^{f}+2 t+2 \operatorname{vot}_{l} \eta_{h} \frac{q_{1}+q_{2}}{\lambda}}{\lambda}+c^{q}\right]-q_{i} \frac{2 v o t_{l} \eta_{h}}{\lambda^{2}}=0}
\end{aligned}
$$

Each additional passenger transported by airline $i$ causes a marginal direct congestion cost $q_{i} 2 \eta_{h} \operatorname{vot}_{l} / \lambda^{2}$ for both airline $i$ and airline $-i$, which is the increase in operating costs for other passengers transported. Likewise, a marginal congestion cost of $2 \eta_{h} v o t_{p} / \lambda$ is imposed on the passengers transported by both airline $i$ and airline $-i$, which can be seen as andirect congestion cost from an airline's perspective, in the sense that it reduces the passengers' willingness to pay for a ticket. From the first-order condition for profit maximization, it is apparent that airline $i$ only internalizes the congestion incurred by itself and its passengers (the last LHS-term and the fourth LHS-term respectively). Because the airlines have the same outputs in the symmetric equilibrium, it follows that the airlines internalize half of the congestion they cause (the same result is obtained by Brueckner [5]). Solving the first-order conditions yields the following equilibrium outputs:

$q_{1}=q_{2}=\frac{1}{3} \frac{\lambda\left[\alpha \lambda-2 t-c^{f}-\lambda c^{q}\right]}{\beta \lambda^{2}+2 \eta\left(\lambda v o t_{p}+v o t_{l}\right)}$

which are positive when

$$
\alpha \lambda_{l}>2 t+c^{f}+\lambda c^{q}
$$

The latter condition simply states that outputs are positive when the highest reservation price $(\alpha)$ multiplied by the load, exceeds the average cost of the service.

From the first-order condition and the generalized cost function, we can derive the equilibrium fare: 


$$
p_{i}=\left[\frac{1}{\lambda}\left(c_{i}^{f}+2 t+2 \operatorname{vot}_{l} \eta_{h} \frac{q_{1}+q_{2}}{\lambda}\right)+c^{q}\right]+q_{i}\left(\beta+\frac{2 v o t_{p} \eta_{h}}{\lambda}+\frac{2 v o t_{l} \eta_{h}}{\lambda^{2}}\right), \quad \forall i=1,2
$$

The first RHS-term (in square brackets) is the airline's operating cost per passenger. The second RHS-term is a mark-up consisting of two terms: (i) $q_{i}\left(2 \eta_{h} / \lambda\right)\left(\operatorname{vot}_{p}+\operatorname{vot}_{l} / \lambda\right)$ reflects the firm-internal direct and indirect congestion costs; and (ii) $q_{i} \beta$ reflects a market power effect, which as expected increases when demand becomes less elastic (evaluated in the equilibrium). The internalization of congestion externalities as such is consistent with efficient price setting, although the neglect of those imposed on the other airline and its passengers is not. The market power effect is not consistent with efficient pricing.

It follows from (12) that the equilibrium value for $q_{i}$ is a function of the toll $t$. The optimal toll is determined by the regulator, and is derived in the next subsection.

\section{The regulator's maximization problem}

From the analysis in the preceding subsection, it is clear that there are potential distortions in equilibrium price setting due to non-internalized congestion externalities, and duopolistic pricing. In this section, we consider strategies for a regulator to deal with these inefficiencies.

In terms of objectives, we consider welfare-maximizing regulation. Since there is a market-power effect, which requires a subsidy when considered in isolation, the resulting optimal toll may very well be negative. Because both airlines have the same operating characteristics, and demand is shared evenly between the carriers, a regulator will set only one toll; this toll is paid by both airlines for the use of both airports. In an asymmetric equilibrium, differentiated tolls $t_{h, i}$ would typically be necessary. The same applies for non-cooperating regulators (as in Section 5).

The global regulator maximizes surplus for the entire network: the regulator considers consumer surplus and profits of both operators. It sets a common toll $t$ for both nodes $h$ in the system. The regulator's maximization problem is:

$$
\begin{aligned}
& \max _{\mathrm{q}_{\mathrm{i}}} \varpi_{G}= \\
& \int_{0}^{q_{1}+q_{2}}(\alpha-\beta x) d x-2\left(q_{1}+q_{2}\right) \frac{\left(q_{1}+q_{2}\right) \operatorname{vot}_{p} \eta_{h}}{\lambda}-\left(q_{1}+q_{2}\right)\left[\frac{1}{\lambda_{i}}\left(c^{f}+\operatorname{vot}_{l} \frac{q_{1}+q_{2}}{\lambda}\right)+c^{q}\right]
\end{aligned}
$$

The first RHS-term represents total benefits (as integral of the Marshallian inverse demand function). The second RHS-term represents total generalized costs (excluding the airline fares, 
which cancel out against the airline revenues). The third RHS-term represents airline operating costs (excluding the expenditures on tolls, which cancel out against toll revenues). The three terms together thus give social surplus.

Comparing the first-order conditions for welfare maximization and profit maximization yields:

$$
\frac{\partial \varpi_{G}}{\partial q_{i}}-\frac{\partial \pi_{G}}{\partial q_{i}}=-q_{-i} \frac{2 \eta_{h}}{\lambda}\left(v o t_{p}+\frac{v o t_{l}}{\lambda}\right)+q_{i} \beta+\frac{2 t}{\lambda}
$$

where the first RHS-term is the congestion that is not internalized by carrier $i$ and the second RHS-term is the market power effect. The third RHS-term is the toll per passenger (for a return flight). To calculate the welfare optimizing toll, it is necessary that (14) equals zero. Solving this equation for $t$ yields (the superscript ${ }^{w}$ indicates a welfare maximizing toll):

$$
t^{w}=\frac{\lambda}{2}\left[q_{-i} \frac{2 \eta_{h}}{\lambda}\left(\operatorname{vot}_{p}+\frac{\operatorname{vot}_{l}}{\lambda}\right)-q_{i} \beta\right]
$$

In the symmetric equilibrium, $q_{-i}=q_{i}$, so that the first-best welfare maximizing toll is negative when the congestion effect $q_{i}\left(2 \eta_{h} / \lambda\right)\left(\operatorname{vot}_{p}+\operatorname{vot}_{l} / \lambda\right)$ is smaller than the market power effect $q_{i} \beta$

Substituting the toll rule (15) into the optimal output (10), and taking into account that $q_{i}=q_{-i}$ in the symmetric equilibrium, yields the optimal quantity per airline (the superscript ${ }^{w}$ again indicates a welfare maximizing quantity):

$$
q^{w}=\frac{\lambda\left(\alpha \lambda-c^{f}-\lambda c^{q}\right)}{2 \beta \lambda^{2}+8 \eta\left(\lambda v o t_{p}+v o t_{l}\right)}
$$

This optimal output implies the following closed-form optimal toll-level:

$$
t^{w}=\frac{\left(\alpha \lambda-c^{f}-\lambda c^{q}\right)\left[2 \eta_{h}\left(v^{2} t_{p} \lambda+v o t_{l}\right)-\lambda^{2} \beta\right]}{4 \beta \lambda^{2}+16 \eta\left(\lambda v o t_{p}+v o t_{l}\right)}
$$

which, again, is negative when the market power effect exceeds the congestion effect.

Because negative tolls (subsidies) may not be politically viable in practice, the regulator may impose a non-negativity constraint. As long as the market power effect exceeds the congestion effect, the resulting toll will equal zero. The corresponding outputs are given in (10) (with $t=0$ ).

Brueckner [5] proposes another toll-rule, which we will call the 'pure congestion toll' $t^{c}$. With this toll, the airlines are charged for the congestion that is not internalized: 


$$
t^{c}=q_{-i} \eta_{h}\left(\operatorname{vot}_{p}+\frac{\operatorname{vot}_{l}}{\lambda}\right)
$$

which is necessarily positive when $q>0$ (i.e. when (11) holds). Substituting (18) into (10) yields:

$$
\begin{aligned}
q^{c} & =\frac{\lambda\left(\alpha \lambda-c^{f}-\lambda c^{q}\right)}{3 \beta \lambda^{2}+8 \eta\left(\lambda v o t_{p}+v o t_{l}\right)} \\
t^{c} & =\frac{\left(\alpha \lambda-c^{f}-\lambda c^{q}\right) \eta\left(\lambda v o t_{p}+v o t_{l}\right)}{3 \beta \lambda^{2}+8 \eta\left(\lambda v o t_{p}+v_{l}\right)}
\end{aligned}
$$

When we compare the welfare optimizing output in (16) with the "congestion optimizing output' in (19), we see that the latter never exceeds the former (because the denominator is larger). Congestion, when considered in isolation, requires a positive toll to induce a reduction in the outputs; this toll is given in equation (18). Only when demand is perfectly elastic $(\beta=0)$, the market power effect vanishes and the toll in (18) becomes overall optimal and equal to that in (15), and also (20) and (17) become equal (i.e., $t^{c}=t^{w}$ ). The outputs in (10) are also adjusted accordingly (i.e. are set at the welfare maximizing level), which can be verified from the resulting equality of (19) and (16).

When the market power effect exceeds the congestion effect, a subsidy is necessary when welfare is to be maximized, so that the airlines will increase their outputs to the welfare optimizing level. When this market power effect is ignored and a positive congestion toll $t^{c}$ is implemented $\left(t^{c}>0\right)$, outputs will be decreased rather than increased, and welfare will reduce. The toll $t^{c}$ certainly becomes welfare reducing when $t^{w}$ is negative. This also defines the point where a zero toll would be the optimal choice when - for political reasons - it is decided that subsidization of airlines is not warranted, and $t^{w}$ would be constrained to be non-negative.

The closed-form welfare levels for the three toll levels of interest (welfare maximizing, congestion tolling and no toll) are presented in Table 1; these are obtained by substituting the associated equilibrium outputs into the welfare function. 


\begin{tabular}{ll}
\hline toll regime & Welfare level \\
\hline$t=t^{w}$ & $\omega^{w}=\frac{1}{2} \frac{\left(\lambda c^{f}+\lambda c^{q}-\alpha\right)^{2}}{\beta \lambda^{2}+4 \eta\left(\lambda v o t_{p}+v o t_{l}\right)}$ \\
$t=t^{c}$ & $\omega^{c}=\frac{\left(\lambda c^{f}+\lambda c^{q}-\alpha\right)^{2}\left[\beta \lambda^{2}+2 \eta\left(\lambda v o t_{p}+v o t_{l}\right)\right]}{\left[3 \beta \lambda^{2}+8 \eta\left(\lambda v o t_{p}+v o t_{l}\right)\right]^{2}}$ \\
$t=0$ & $\omega^{0}=\frac{4}{9} \frac{\left(\lambda c^{f}+\lambda c^{q}-\alpha\right)^{2}\left[\beta \lambda^{2}+\eta\left(\lambda v o t_{p}+v o t_{l}\right)\right]}{\left[\beta \lambda^{2}+2 \eta\left(\lambda v o t_{p}+v_{l} t_{l}\right)\right]^{2}}$ \\
\hline
\end{tabular}

Table 1. Closed-form welfare levels for different toll regimes

It is straightforward that $\omega^{w} \geq \omega^{c}$ and $\omega^{w} \geq \omega^{0}$; this follows from the definition of the optimization problem. These inequalities can be shown to hold for any parameter constellation. More interesting is the comparison of $\omega^{c}$ and $\omega^{0}$. Subtracting the two welfare levels yields (still in closed form):

$\omega^{c}-\omega^{0}=$
$\frac{4}{9} \frac{\left(\lambda c^{f}+\lambda c^{q}-\alpha\right)^{2} \eta\left(\lambda v o t_{p}+v t_{l}\right) \Psi}{\left[3 \beta \lambda^{2}+8 \eta\left(\lambda v o t_{p}+v_{l}\right)\right]^{2}\left[\beta \lambda^{2}+2 \eta\left(\lambda v o t_{p}+v^{2} t_{l}\right)\right]^{2}}$

where

$\Psi=-3 \beta^{2} \lambda^{4}-4 \lambda^{2} \eta\left(v t_{k}+\lambda v o t_{p}\right) \beta+8 \eta^{2}\left[\lambda^{2} v_{p}^{2}+v_{p}^{2}+2 \lambda v o t_{p} v_{k} t_{k}\right]$

It is clear that $\omega^{c}-\omega^{0}>0$ when $\psi>0$. Because $\psi$ is a quadratic function of $\beta$ with a negative coefficient for the squared term, $\psi>0$ for any value of $\beta$ between the two roots of $\psi$. Solving $\psi=0$ for $\beta$ yields the following two roots:

$\beta_{1}=4 \frac{\left(-\frac{1}{6}-\frac{1}{6} \sqrt{7}\right) \eta\left(\lambda v o t_{p}+\operatorname{vot}_{l}\right)}{\lambda^{2}}=-2.431 \frac{\eta\left(\lambda v o t_{p}+v_{l}\right)}{\lambda^{2}}$
$\beta_{2}=4 \frac{\left(-\frac{1}{6}+\frac{1}{6} \sqrt{7}\right) \eta\left(\lambda v o t_{p}+v_{l}\right)}{\lambda^{2}}=1.097 \frac{\eta\left(\lambda v o t_{p}+v_{l}\right)}{\lambda^{2}}$

It follows that $\omega^{c}-\omega^{0} \geq 0$ for $\beta \in\left[-2.431 \frac{\eta\left(\lambda v o t_{p}+v o t_{l}\right)}{\lambda^{2}}, 1.097 \frac{\eta\left(\lambda v o t_{p}+v o t_{l}\right)}{\lambda^{2}}\right]$, where the lower bound is economically irrelevant (because it implies that $\beta<0$ and hence the slope of the 
inverse demand function would be positive). When $\beta$ is larger than the upper bound of this interval, the congestion toll leads to a welfare degradation compared to no-toll scenario.

From equation (17) we know that the market power effect dominates the congestion effect when $\beta>2 \eta_{h}\left(\operatorname{vot}_{p} \lambda+v_{\text {ot }}\right) / \lambda^{2}$. We will denote this compactly as $\beta^{*}>2$, with $\beta^{*}$ defined as $\beta \cdot\left(\eta_{h}\left(\operatorname{vot}_{p} \lambda+v_{0}\right) / \lambda^{2}\right)^{-1}$. When this is the case, the welfare maximizing toll is negative. When the inequality is reversed $\left(\beta^{*}<2\right)$, the congestion effect dominates and the welfare maximizing toll is positive. For any $\beta^{*}$ between 1.097 and 2 , the welfare maximizing toll is positive, while the pure congestion toll (despite its correct sign) already leads to a welfare loss. This reflects that the welfare maximizing toll gets relatively close to zero, and relatively far below the pure congestion toll.

Figure 1 summarizes these findings. The line just above $\beta^{*}$ shows the sign of the welfare maximizing toll $t^{w}$, and the upper line that of $\omega^{c}-\omega^{0}$.

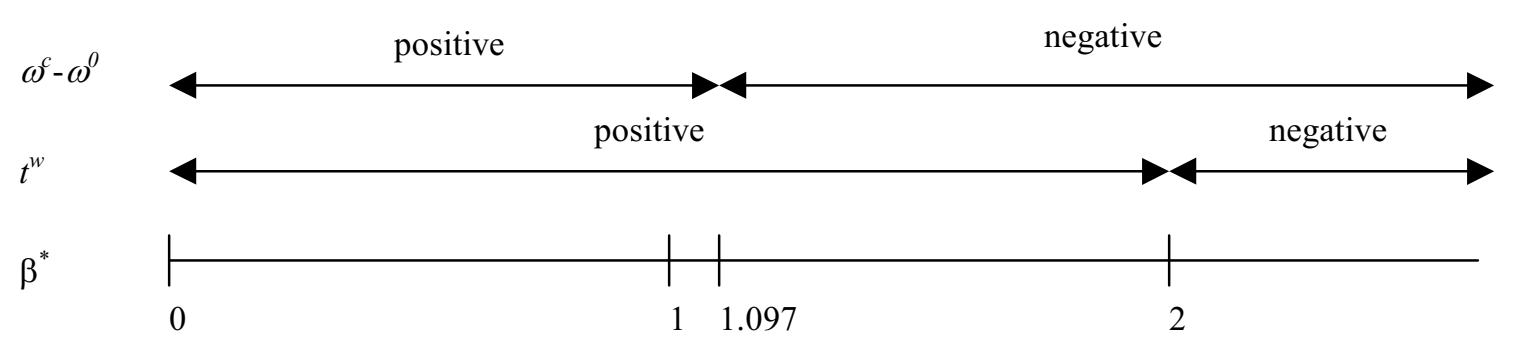

Figure 1. Optimality of the pure congestion toll

In summary, a welfare maximizing regulator should set a toll that captures both (firmexternal) congestion externalities and the market power effect. This toll can be negative. If a negative toll is not feasible, then the regulator should set a zero toll when the market power effect dominates the congestion effect $\left(\beta^{*}>2\right.$ in the symmetric case). The pure congestion toll $t^{c}$ coincides with the optimal toll only if the market power effect vanishes $(\beta=0)$.

\section{NUMERICAL EXAMPLES}

This section will present some numerical results that further illustrate the comparative static properties of our model. We will begin with a symmetric case, and then move on to an asymmetric set-up. 


\subsection{Symmetric case}

Table 2 shows the parametrization for the symmetric case. As stated, it is not the purpose of this paper to accurately describe a real-life aviation network. The parameters therefore need not correspond to real life values. However, we will calculate the equilibrium price elasticity of demand and compare this to estimates from the literature, and will check the ratio of passengers' congestion costs to generalized costs, and airlines' congestion costs to total operating costs, to confirm the plausibility of the parametrization.

\begin{tabular}{|c|c|c|c|c|c|c|c|c|c|}
\hline & land $c$ & teris & & \multicolumn{4}{|c|}{ Airline characteristics } & \multicolumn{2}{|c|}{ Node characteristics } \\
\hline$\alpha$ & 5000 & $v t_{p}$ & 50 & $c^{f}$ & 100000 & $\lambda$ & 200 & $\eta$ & 0.5 \\
\hline$\beta$ & 1 & & & $c^{q}$ & 100 & vot $_{l}$ & 500 & & \\
\hline
\end{tabular}

Table 2. Parameter values for the symmetric numerical model

Table 3 gives the no-toll equilibrium. The calculated price elasticity in equilibrium of -1.15 roughly corresponds to the value of -1.146 reported by Brons et al. [3] (the variable $\varepsilon$ will be used to indicate the absolute value of demand elasticity with respect to generalized costs). The latter figure is the overall mean of 204 estimates from the literature. This suggests that we operate on a relevant segment of the demand curve. Passenger congestion costs are some $20 \%$ of their generalized costs, while for the airlines, congestion costs amount to some $5 \%$ of their total operating costs. Also these figures appear reasonable. The higher figure for passengers would reflect that they incur congestion costs in the terminal, in addition to those in the air.

\begin{tabular}{lccccccc}
\hline & \multicolumn{4}{c}{ generalized costs } & \multicolumn{3}{c}{ welfare effects } \\
airline 1 & 1162 & fare & congestion & $\varepsilon$ & consumer surplus & profits & welfare \\
airline 2 & 1162 & 2096 & 581 & 1.15 & $1.35 \cdot 10^{6}$ & $0.70 \cdot 10^{6}$ & $2.05 \cdot 10^{6}$ \\
total & 2324 & & 581 & 1.15 & $1.35 \cdot 10^{6}$ & $0.70 \cdot 10^{6}$ & $2.05 \cdot 10^{6}$ \\
\hline
\end{tabular}

Table 3. Equilibrium outputs and welfare: no toll

Table 4 gives the equilibrium for the (first-best) welfare maximizing toll $t^{w}$. The toll is negative, and quite large in absolute value (compared to, for instance, the marginal cost per flight). The negative sign reflects that the market power effect in the no-toll equilibrium exceeds the congestion effect. Because the airlines receive substantial subsidies, the optimal outputs and profits are larger than in the no-toll equilibrium. Because the optimal outputs are 
higher, congestion costs are also higher. Without tolls, the airlines set their equilibrium outputs too low, and as a result, the congestion costs are too low in the optimum. The welfare maximizing toll fixes this problem. When this welfare maximizing toll is implemented, overall welfare increases by $6 \%$ compared to the base case; this is the maximum possible increase in welfare.

\begin{tabular}{lccccccccc}
\hline & $\mathrm{q}$ & \multicolumn{2}{c}{ generalized costs } & $\varepsilon$ & toll & \multicolumn{4}{c}{ welfare effects } \\
& & fare & congestion & & & consumer & profits & toll & welfare \\
airline 1 & 1443 & 1393 & 721 & 0.73 & $-0.11 \cdot 10^{6}$ & $2.08 \cdot 10^{6}$ & $1.63 \cdot 10^{6}$ & $-1.53 \cdot 10^{6}$ & $2.17 \cdot 10^{6}$ \\
airline 2 & 1443 & 1393 & 721 & 0.73 & $-0.11 \cdot 10^{6}$ & $2.08 \cdot 10^{6}$ & $1.63 \cdot 10^{6}$ & $-1.53 \cdot 10^{6}$ & $2.17 \cdot 10^{6}$ \\
total & 2886 & 2786 & & & & $4.16 \cdot 10^{6}$ & $3.26 \cdot 10^{6}$ & $-3.06 \cdot 10^{6}$ & $4.34 \cdot 10^{6}$ \\
\hline
\end{tabular}

Table 4. Equilibrium outputs and welfare: first-best welfare maximizing toll

The equilibrium in Table 4 may be of limited practical interest, because subsidizing airlines may be considered politically unacceptable. An alternative would then be to impose a nonnegativity constraint on the toll. The result is the no-toll equilibrium in Table 3, where overall welfare (consumer surplus plus profits excluding tolls) is of course lower than in Table 4.

We have already shown that a pure congestion toll $t^{c}$ is not optimal. We now determine the welfare effects of a pure congestion toll for our numerical model. Table 5 contains the relevant information.

\begin{tabular}{lccccccccc}
\hline & $\mathrm{q}$ & \multicolumn{2}{c}{ generalized costs } & $\varepsilon$ & toll & \multicolumn{4}{c}{ welfare effects } \\
fare & congestion & & & $\begin{array}{c}\text { consumer } \\
\text { profits }\end{array}$ & toll & welfare \\
airline 1 & 1086 & 2284 & 543 & 1.30 & 28519 & $1.18 \cdot 10^{6}$ & $0.49 \cdot 10^{6}$ & $0.31 \cdot 10^{6}$ & $1.98 \cdot 10^{6}$ \\
airline 2 & 1086 & 2284 & 543 & 1.30 & 28519 & $1.18 \cdot 10^{6}$ & $0.49 \cdot 10^{6}$ & $0.31 \cdot 10^{6}$ & $1.98 \cdot 10^{6}$ \\
total & 2172 & & & & & $2.36 \cdot 10^{6}$ & $0.98 \cdot 10^{6}$ & $0.62 \cdot 10^{6}$ & $3.96 \cdot 10^{6}$ \\
\hline
\end{tabular}

Table 5. Equilibrium outputs and welfare: pure congestion toll

The toll $t^{c}$ is positive (as expected), and this is also reflected in consumer prices: the airlines pass the (part of) the expenditures on the toll onto the passengers. Because the fares increase, consumer surplus decreases compared to the no-toll equilibrium. Airline profits decrease, because the reduction in airline congestion costs does not outweigh the expenditures on the congestion toll. We already concluded that in the no-toll equilibrium, the airlines set their equilibrium outputs too low. The pure congestion toll causes the outputs to be even lower. The decrease in welfare is around $61 \%$ of the maximum possible increase in welfare: $\Omega^{c}=\left(\omega^{c}\right.$ - 
$\left.\omega^{0}\right) /\left(\omega^{w}-\omega^{0}\right)=-0.61$ (with $\Omega^{\mathcal{C}}$ denoting the relative efficiency gain due to pure congestion pricing). For the chosen parameter constellation, the welfare decrease is therefore substantial.

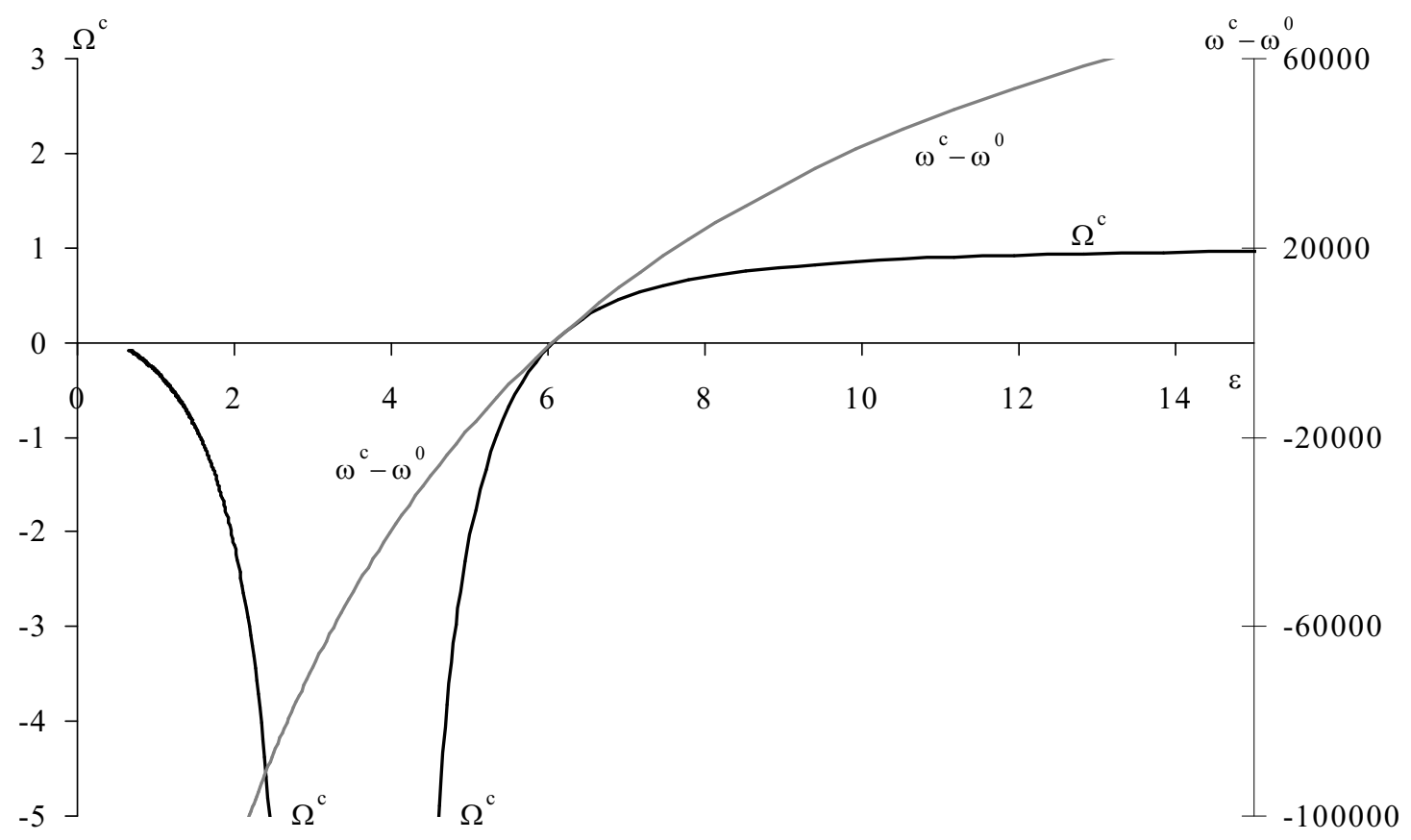

Figure 2. Welfare effects of pure congestion tolling $t^{c}$

Because the difference between the optimal welfare toll $t^{w}$ and the pure congestion toll $t^{c}$ depends crucially on the elasticity of demand (as explained in Section 3), it is of interest to see how $\Omega^{C}$ varies with the (absolute value of) the equilibrium demand elasticity, $\varepsilon$. Figure 2 shows the results (which were obtained numerically by simultaneously adjusting $\alpha$ and $\beta$ so that the same no-toll equilibrium was obtained for each $\varepsilon$ shown) ${ }^{6}$. Only for rather high elasticities, above 6 in absolute value, does $t^{c}$ yield a positive welfare effect (indicated by a positive value of $\Omega^{\mathfrak{C}}$ ). This is where the congestion effect sufficiently outweighs the market power effect (compare Figure 1). For lower elasticities, $\Omega^{f}$ approaches $-\infty$ for that particular combination of $\alpha$ and $\beta$ for which both $t^{w}$ and its welfare effects become zero, because the congestion effect and the market power effect exactly cancel (for $\varepsilon$ near 3.55 in the diagram). The grey line - depicting the absolute welfare change due to $t^{c}$ - shows that also at that point,

\footnotetext{
${ }^{6}$ Because the issue here is the effect of market power, and not the effect of initial demand on the optimality of the toll, the reservation price $\alpha$ is varied together with $\beta$ so as to obtain the same no-toll equilibrium in terms of quantities $q_{1}$ and $q_{2}$. This was realized technically by treating $q_{1}$ and $q_{2}$ parametrically in equation (9), and solving for $\alpha$ as a function of $\beta$ for the resulting equation (keeping all other parameters fixed).
} 
substantial welfare losses due to pure congestion pricing occur, so that it is not solely a denominator-effect in $\Omega^{\mathcal{C}}$ that makes $t^{c}$ appear harmful to efficiency. For yet lower elasticities, their numerical values become more plausible from an empirical perspective, but $\Omega^{\mathscr{C}}$ remains negative. It approaches zero from below as demand becomes perfectly inelastic, in which case symmetric tolls for symmetric duopolists will not affect symmetric demand levels, and hence congestion levels anymore.

Figure 1 implies that patterns as in Figure 2 will be found also for other parameter constellations. In particular, note that moving from right to left in Figure 1 means moving from left to right in Figure 2. When doing so, we therefore always expect $\Omega^{\mathscr{C}}$ to be negative near perfect inelasticity of demand (for high values of $\beta^{*}$, on the left end of Figure 2 and the right end of Figure 1), to fall to $-\infty$ when $\beta^{*}$ falls to 2 , to remain negative as long as $\beta^{*}$ exceeds 1.097 , and to increase above zero when $\beta^{*}$ falls below 1.097 - approaching unity as demand elasticity approaches infinity.

It is of course the particular parametrization of the numerical model that causes the welfare effect of $t^{c}$ to become positive only for demand elasticities above an unrealistically high value of 6 (in absolute value) in Figure 2. Intuition suggests that when congestion would become relatively more important, one would expect this critical $\varepsilon$ to fall (this also follows from equation (23) and Figure 1). To verify this, we plot in Figure 3 the curve $\Omega^{\mathcal{C}}=0$ (which is equivalent with $\omega^{c}=\omega^{0}$ ) for various combinations of values of $\eta$ and $\varepsilon$, again such that equilibrium demand levels remain unaltered ${ }^{7}$. The lower curve in Figure 3 gives the combinations of $\varepsilon$ and $\eta$ for which the market power effect equals the congestion effect (i.e. $\left.\omega^{w}=\omega^{0}\right)$. To the left of this curve, the market power effect exceeds the congestion effect $\left(\beta>2 \eta_{h}\left(\operatorname{vot}_{p} \lambda+\operatorname{vot}_{l}\right) / \lambda^{2}\right)$, so that a subsidy is required; a pure congestion toll then cannot be optimal. From the upper curve in Figure $3\left(\Omega^{\mathcal{C}}=0\right)$, we may conclude that the elasticity at which a pure congestion toll is not welfare reducing decreases when congestion $(\eta)$ increases.

The lower limit to the elasticity at which a pure congestion toll ceases to cause welfare losses, as discussed above, varies with $\eta$, $v_{p} t_{p}, v_{l}$ and $\lambda$. A decrease in $\lambda$ keeping $\eta$ fixed, for

\footnotetext{
${ }^{7}$ Following the procedure described in footnote $4, \alpha$ can be expressed in $\beta$ and $\eta$. After substituting this expression for $\alpha$ in $\Omega^{\mathscr{C}}$, and given $\eta$, one can solve $\Omega^{\mathcal{C}}=0$ for $\beta$, which is then transformed into an elasticity.
} 
example, would move the two curves in Figure 3 to the left. ${ }^{8}$ The reason is that this is another way of making congestion relatively more important.

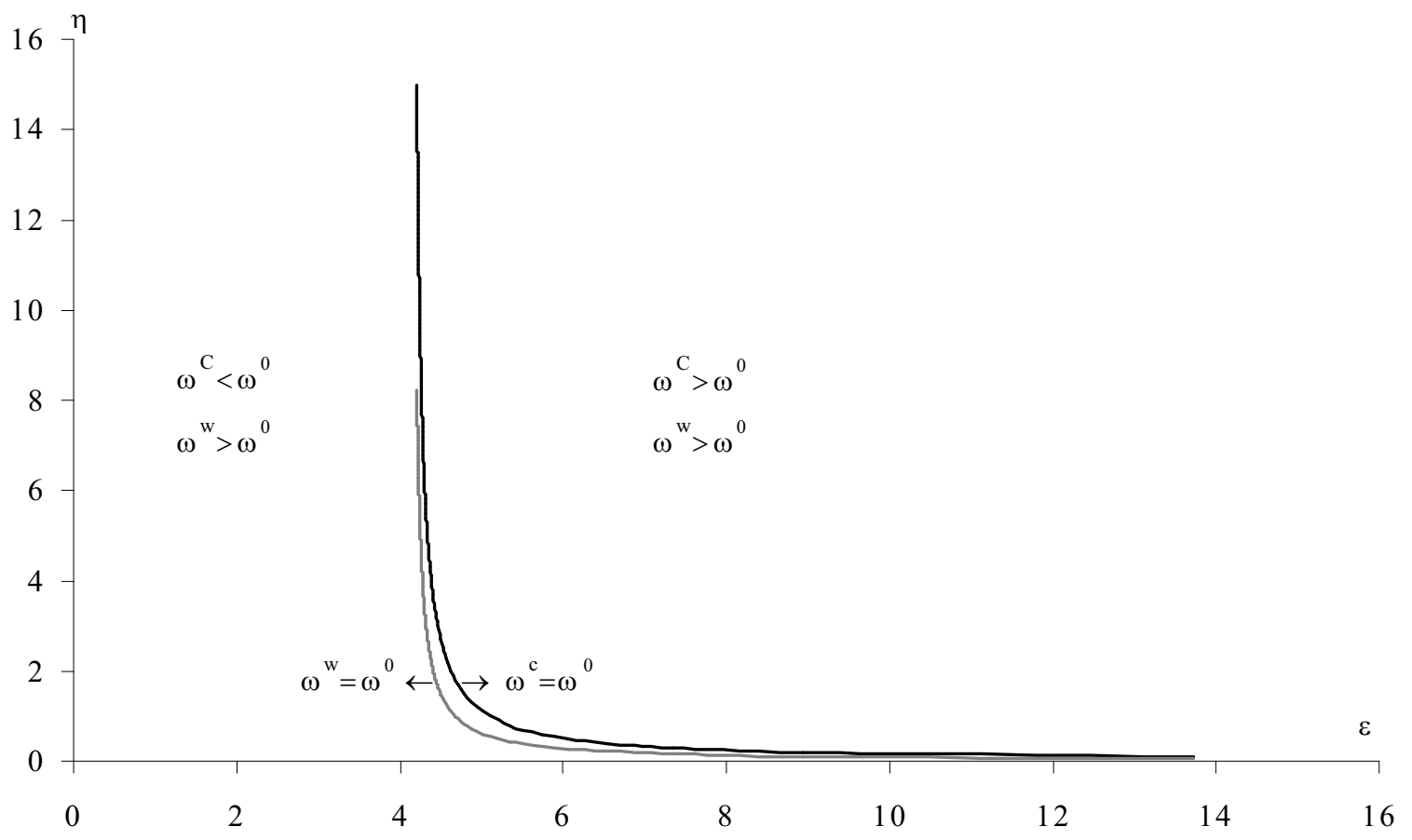

Figure 3. Optimality of pure congestion tolling $t^{c}$

\subsection{An asymmetric numerical model}

It is interesting to briefly investigate some implications of introducing differences between airlines in the above model. As stated, this makes the analytics of the model cumbersome, but the numerical model still produces intuitive results. We increase airline 2's aircraft capacity by $10 \%$, and we reduce airline's 2 cost per passenger and flight by $10 \%$ (see Table 6 ). This parameter constellation more or less reflects the situation of entry of a low-cost carrier in a market that used to be served by a ("conventional") monopolist, although the increase in aircraft capacity and decrease in costs is chosen arbitrarily. Note that the airports remain identical.

\footnotetext{
${ }^{8}$ At the given parametrization (and with $\left.\lambda=200\right), \omega^{w}=\omega^{0}$ if $\eta=(40 / 21) \beta$. For $\lambda=100, \omega^{w}=\omega^{0}$ if $\eta=(10 / 11) \beta$. This indicates that the entire curve shifts to the left when the aircraft load is reduced. For instance, at $\varepsilon=3, \eta=0.33$ when $\lambda=100$. When $\lambda=200, \eta=0.33$ at $\varepsilon=5.7$. To save space, no plot similar to Figure 3 was made for $\lambda=100$. Details are available upon request.
} 


\begin{tabular}{|c|c|c|c|c|c|c|c|c|c|c|c|c|}
\hline \multicolumn{4}{|c|}{ Demand characteristics } & \multicolumn{8}{|c|}{ Airline characteristics } & \multirow{2}{*}{$\begin{array}{l}\text { Node characteristics } \\
\eta\end{array}$} \\
\hline$\alpha$ & 5000 & $v t_{p}$ & 50 & $c_{1}^{\mathrm{f}}$ & 100000 & $c_{1}^{f}$ & 90000 & $\lambda_{1}$ & 200 & vot $_{l}$ & 500 & \\
\hline$\beta$ & 1 & & & $\mathrm{c}_{2}^{\mathrm{q}}$ & 100 & $\mathrm{c}_{2}^{\mathrm{q}}$ & 90 & $\lambda_{2}$ & 220 & & & \\
\hline
\end{tabular}

Table 6. Parameter values for the asymmetric model

The resulting equilibrium is given in Table 7. Competition combined with the passengers' equilibrium conditions forces the airlines to charge the same ticket price, despite their different cost structures. As a result, the more efficient airline 2 will enjoy a greater patronage and higher profits in equilibrium. The inefficient airline 1, however, remains in operation.

\begin{tabular}{lccccccc}
\hline & \multicolumn{4}{c}{ generalized costs } & \multicolumn{3}{c}{ welfare effects } \\
airline 1 & 1134 & fare & congestion & $\varepsilon$ & consumer surplus & profits & welfare \\
airline 2 & 1240 & 2060 & 565 & 1.11 & $1.35 \cdot 10^{6}$ & $0.62 \cdot 10^{6}$ & $1.97 \cdot 10^{6}$ \\
total & 2374 & & 565 & 1.11 & $1.47 \cdot 10^{6}$ & $0.90 \cdot 10^{6}$ & $2.37 \cdot 10^{6}$ \\
\hline
\end{tabular}

Table 7. Equilibrium outputs and welfare in the asymmetric setting: no toll

For this asymmetric case, we obtain the following equivalent of (14) for the calculation of optimal airline specific tolls:

$\frac{\partial \varpi_{G}}{\partial q_{i}}-\frac{\partial \pi_{G}}{\partial q_{i}}=-q_{-i} \frac{2 \eta_{h}}{\lambda_{-i}}\left(\operatorname{vot}_{p}+\frac{\operatorname{vot}_{l}}{\lambda_{-i}}\right)+q_{i} \beta+\frac{2 t_{i}}{\lambda_{i}}$

from which the optimal tolls $t^{w}$ can be derived as:

$t^{w}=\frac{\lambda_{i}}{2}\left[q_{-i} \frac{2 \eta_{h}}{\lambda_{-i}}\left(\operatorname{vot}_{p}+\frac{v o t_{l}}{\lambda_{-i}}\right)-q_{i} \beta\right]$

which is a straightforward generalization of (15). The relevant $t^{c}$ can be derived from (25) by - again - removing the market power effect, and is identical to (18) with $\lambda_{-i}$ substituted for $\lambda$.

The asymmetry has various consequences. First, absent congestion, only one airline would survive in the economic optimum. Starting in the no-toll equilibrium, the subsidy per passenger would be larger for the larger (more efficient) airline, which would then expand services, obtain a yet larger subsidy, and so on, until the other airline is pushed out of the market. Secondly, it is very likely that with congestion, this effect is aggravated, because the larger airline will typically cause relatively low external congestion costs, as most congestion costs caused are firm-internal (only under strong asymmetries in $\lambda$ might this not be the case).

With the chosen parameter values, airline 1 is indeed pushed out of business when the regulator sets welfare maximizing tolls. A first, economically irrelevant solution (which is 
therefore not reported) shows that the toll for airline 1 is positive, and that airline 1's resulting optimal output is negative. In other words, airline 1 pulls out of the market. Readjusting the model to the new situation results in the optimum in Table 8 . Because the monopoly airline internalizes all congestion, the toll in Table 8 is solely a response to its market power.

\begin{tabular}{ccccccccccc}
\hline & $\mathrm{q}$ & \multicolumn{2}{c}{ generalized costs } & $\varepsilon$ & toll & \multicolumn{4}{c}{ welfare effects } \\
& & fare & congestion & & & consumer & profits & toll & welfare \\
airline 2 & 3051 & 1256 & 693 & 0.64 & $-0.34 \cdot 10^{6}$ & $4.65 \cdot 10^{6}$ & $10.52 \cdot 10^{6}$ & $-9.31 \cdot 10^{6}$ & $5.86 \cdot 10^{6}$ \\
\hline
\end{tabular}

Table 8. Equilibrium outputs and welfare in the asymmetric setting: first-best welfare maximizing toll

When non-negativity constraints are imposed, airline 2's toll will be equal to 0 . In that case, it sets its output below the welfare optimizing output, leaving some room for airline 1 to reenter the market (or to remain in business). Fixing the toll for airline 2 at 0 and solving for the optimal toll for airline 1 yields a negative toll, so that also for airline 1 the non-negativity constraint becomes binding. The eventual result is the no-toll equilibrium reported in Table 7 .

In this case, the relatively inefficient airline remains in business. Moreover, aggregate consumer surplus is much lower compared to Table 8 , because outputs are set below the welfare economic optimum. Welfare (consumer surplus plus profits excluding tolls) is $35 \%$ higher when a welfare maximizing 'toll' is set by the regulator than without tolling.

Next, we compare the welfare economic performance of a pure congestion toll to the welfare economic performance of a zero toll. Table 9 shows that both tolls are positive, whereas welfare maximization would require one subsidized supplier. We can therefore conclude that at the chosen parameter constellation, the pure congestion toll is again welfare reducing compared to the base case of the zero toll.

\begin{tabular}{lccccccccc}
\hline & $\mathrm{q}$ & \multicolumn{2}{c}{ generalized costs } & $\varepsilon$ & toll & \multicolumn{4}{c}{ welfare effects } \\
& & fare & congestion & & & consumer & profits & toll & welfare \\
airline 1 & 1062 & 2243 & 530 & 1.25 & 27677 & $1.18 \cdot 10^{6}$ & $0.42 \cdot 10^{6}$ & $0.29 \cdot 10^{6}$ & $1.89 \cdot 10^{6}$ \\
airline 2 & 1165 & 2243 & 530 & 1.25 & 30652 & $1.30 \cdot 10^{6}$ & $0.68 \cdot 10^{6}$ & $0.32 \cdot 10^{6}$ & $2.30 \cdot 10^{6}$ \\
total & 2227 & & & & & $2.48 \cdot 10^{6}$ & $1.1 \cdot 10^{6}$ & $0.61 \cdot 10^{6}$ & $4.19 \cdot 10^{6}$ \\
\hline
\end{tabular}

Table 9. Equilibrium outputs and welfare in the asymmetric setting: pure congestion tolls 


\section{VARIATIONS ON THE REGULATOR'S OPTIMIZATION PROBLEM: LOCAL WELFARE MAXIMIZATION}

The above analysis is based on the assumption that a single regulator regulates both airports. In reality, one may have two (national or regional) regulators, each regulating an airport. An important question then becomes how important it is that these regulators coordinate their activities, instead of pursuing local welfare maximization. For reasons of space, we will consider this issue only briefly, but find it too important to ignore altogether. We assume that both regions host one 'home airline', and that demand is symmetric between regions (i.e., half of any equilibrium demand for return trips concerns trips by consumers from one region, and the other half from the other region). A local regulator in node $h$ would then have the objective of maximizing local welfare as given in (26):

$\varpi_{\mathrm{h}}^{\mathrm{L}}=\frac{1}{2}\left[\int_{0}^{q_{1}+q_{2}}(\alpha-\beta x) d x-\left(\mathrm{q}_{1}+\mathrm{q}_{2}\right)\left[\alpha-\beta\left(\mathrm{q}_{1}+\mathrm{q}_{2}\right)\right]\right]+\pi_{\mathrm{h}}+\sum_{\mathrm{i}=1}^{2} \mathrm{q}_{\mathrm{i}} \frac{\mathrm{t}_{\mathrm{h}, \mathrm{i}}}{\lambda_{\mathrm{i}}}$

The first RHS-term is half of the total consumer surplus. The second RHS-term is the profit of the airline using airport $h$ as its home airport. The third RHS-term is the total toll revenues for regulator $h$. It can be shown that the summation of (26) over $h$ yields total welfare defined in (13) when tolls are undifferentiated (i.e. $t_{h, i}=t_{-h, i}$ ). In absence of policy coordination, we assume that the regulators take the toll of the other regulator as given, and hence exhibit Nash behaviour between them (although both act as a Stackelberg leader with respect to the airlines). For reasons of transparency, we consider the symmetric case, in which airlines have the same operating characteristics, and in which the congestion impact at both airports is the same. Each airport operator then maximizes half of the total welfare, but this of course does not mean that they jointly maximize total welfare. Because the analytical expressions for the locally optimal tolls are not particularly insightful, we immediately proceed with the numerical illustration. The analytical expressions are given in Appendix 1.

A first possibility we consider is when the local regulators could set differentiated tolls (for both airlines). Because the generalized price for consumers is equalized in equilibrium, consumers from both cities can be expected to use both airlines in equal proportions (there are no loyalty programs or nationalistic preferences in our model), and there is no reason to differentiate tolls over both airlines from this perspective (the first term in equation (26)). Likewise, toll revenues (the third term) are equally weighted, independent of which airline pays them, and also for this reason there is no reason to differentiate tolls. The middle term in 
(26) does provide a reason for toll differentiation: only profits for the local airline matter for local welfare.

The third column in Table 10 shows that this gives rise to a substantial toll differentiation in equilibrium: the home carrier's toll is less than $10 \%$ of the foreign carrier's toll. Both tolls are positive, and as a result, welfare deteriorates compared to the no-toll equilibrium $(\Omega=-7.09)$. The closed form toll expressions in Appendix 1 suggest that without policy coordination, equilibrium tolls will always be positive (in symmetric equilibria), for the demand and cost functions we use. The intuition is that subsidization to correct forduopolistic pricing become less attractive from a local regulator's point of view. Only half of the resulting benefits are accounted for in (26): those accruing to the local consumers and airline only. But the full losses are considered: the reduction in local toll revenues. Moreover, a reason arises for further overcharging of the foreign airline, because this raises local toll revenues and indirectly increases local profits as the local airline's competitive position improves.

\begin{tabular}{ccccc}
\hline & $\begin{array}{c}\text { global welfare } \\
\text { maximization }\end{array}$ & zero toll & $\begin{array}{c}\text { local welfare maximization, } \\
\text { differentiated tolls }\end{array}$ & $\begin{array}{c}\text { local welfare maximization, } \\
\text { undifferentiated tolls }\end{array}$ \\
\hline$t_{i}$ & $-0.11 \cdot 10^{6}$ & 0 & $0.033 \cdot 10^{6}$ & $0.196 \cdot 10^{6}$ \\
$t_{-i}$ & $-0.11 \cdot 10^{6}$ & 0 & $0.36 \cdot 10^{6}$ & $0.196 \cdot 10^{6}$ \\
$\omega$ & $2.17 \cdot 10^{6}$ & $2.05 \cdot 10^{6}$ & $1.20 \cdot 10^{6}$ & $1.20 \cdot 10^{6}$ \\
$\Omega$ & 1 & 0 & -7.09 & -7.09 \\
\hline
\end{tabular}

Table 10. Local welfare levels, symmetric equilibrium

When the local regulators are both forced to charge the same, undifferentiated toll for both airlines, a simplistic expectation would be that this toll will be near the average of the differentiated tolls. This, indeed, turns out to be the case, with the noteworthy implication that for overall welfare, it is practically immaterial whether or not local welfare maximizers set differentiated tolls. The closed-form toll expression in Appendix 1 again shows that the undifferentiated toll will always be positive (and confirms its value is near the average of the undifferentiated tolls). In other words: from our results, it appears to be important whether or not airport authorities coordinate their policies when setting congestion tolls. But if they do not do so, it is relatively unimportant whether or not they charge differentiated tolls for the two airlines. 


\begin{tabular}{l|ll}
\hline & & regulator 2 maximizes \\
& regulator 2 sets zero toll & local welfare \\
\hline regulator 1 set zero toll & $2.05 \cdot 10^{6}$ & $0.18 \cdot 10^{6}$ \\
regulator 1 maximizes local welfare & $3.78 \cdot 10^{6}$ & $1.20 \cdot 10^{6}$ \\
\hline
\end{tabular}

Table 11. Local welfare levels at airport 1.

The large discrepancy between welfare under policy coordination and under policy competition makes it likely that some form of coordination would indeed arise in the context we consider. But if it does not, it will not be likely that a status quo with zero tolls would persist. Table 11 gives the relevant pay-offs to regulator 1 (due to symmetry, a similar table applies for regulator 2), and shows that, when starting with zero tolls, regulator 1 has a clear incentive to implement a local welfare maximizing toll. Regulator 2 then (still) has an incentive to do the same, and a classic prisoners dilemma arises in absence of coordination (and for a one shot game).

\section{CONCLUSION}

Conventional economic wisdom suggests that congestion pricing would be an appropriate response to cope with the growing congestion levels currently experienced at many airports. Several characteristics of aviation markets, however, may make naïve congestion prices, equal to the value of marginal travel delays, a non-optimal response. This paper has developed a model of airport pricing that captures some of these features. The model reflects that airlines typically have market power and are engaged in oligopolistic competition, and that a part of external travel delays that aircraft impose are internal to an operator and hence should not be accounted for in congestion tolls. We have also briefly considered the issue of policy coordination between airports.

Some main conclusions are that second-best optimal tolls are typically lower than what would be suggested by congestion costs alone and may even be negative, and that pure congestion tolls, even when corrected for firm-internal congestion, may cause a decrease in welfare when there is significant market power, which in itself would call for subsidization. Brueckner [5] has made clear that congestion tolls on airports may be smaller than expected when congestion costs among aircraft are internal for a firm. He also acknowledged that a pure congestion toll may not be welfare optimal, and may even lead to a welfare degradation 
when the market power effect exceeds uninternalized congestion (without, however, incorporating this in his analytical model). Our paper makes these welfare effects explicit, and shows that the welfare optimal toll is negative when the market power effect exceeds the welfare effect. Insofar as subsidization is considered unacceptable for whichever reason, our results suggest that the most efficient among the non-negative tolls would typically be a zero toll.

We have also seen that policy coordination between airports regulators may be important from an overall welfare perspective. The incentive to adjust tolls downwards to account for market power becomes disproportionally smaller without coordination, which may - as in our model - cause the equilibrium tolls to have the wrong sign and hence to be welfare reducing.

The model in this paper contains a few simplifying assumptions that may be relaxed in future work. Load factors and aircraft capacity are fixed in this model for simplicity. In a more advanced version of this model, load factors and aircraft capacity can be endogenized. One can also add a fourth layer to the model, describing a private airport's profit optimization problem. No distinction is made between peak and off-peak traffic in this paper. This distinction is quite common in the literature (see e.g. Brueckner [5], Daniel [10,11]) and could, as discussed, make a straightforward but important extension of our model. Furthermore, we intend to broaden our analysis to the consideration of larger (hub-and-spoke) networks, that allow consideration of the intriguing question of how congestion (pricing) and market power (regulation) interact when airlines' network configurations are endogenous.

\section{REFERENCES}

1. W.J. Baumol and W.E. Oates, The theory of environmental policy, second edition, Cambridge University Press 1988

2. J.A. Brander and A. Zhang, Market conduct in the airline industry: an empirical investigation, Rand Journal of Economics 21 (1990) 567-583

3. M. Brons, E. Pels, P. Nijkamp and P. Rietveld, Price elasticities of demand for passenger air travel: a meta-analysis, Journal of Air Transport Management, 8 (2002) 165-175.

4. J.K. Brueckner, The economics of international codesharing: an analysis of airline alliances, International Journal of Industrial Organization 19 (2001)1475-1498

5. J.K. Brueckner, Airport congestion pricing when carriers have market power, American Economic Review 92 (2002) 1357-1375.

6. J.K. Brueckner, Internalization of airport congestion: a network analysis, working paper, Institute of Government and Public Affairs, University of Illinois at UrbanaChampaign (2003). 
7. J.K. Brueckner, and P.T. Spiller, Economics of traffic density in a deregulated airline industry, International Journal of Industrial Organization 37 (1991) 323-342

8. J.M. Buchanan, External diseconomies, external taxes, and market structure, American Economic Review 59 (1969) 174-177

9. A. Carlin and R. Park, Marginal cost pricing of airport runway capacity, American Economic Review 60 (1970) 310-319

10. J.I. Daniel, Distributional consequences of airport congestion pricing, Journal of Urban Economics 50 (2001) 230-258.

11. J.I. Daniel, J.I., Congestion pricing and capacity of large hub airports: a bottleneck model with stochastic queues Econometrica 63 (1995) 103-130

12. T.H. Oum, A. Zhang and Y. Zhang, Inter-firm rivalry and firm-specific price elasticities in deregulated airline markets, Journal of Transport Economics and Policy 27 (1993) 171-192

13. T.H. Oum and Y. Zhang, Airport Pricing, Congestion tolls, lumpy investment and cost recovery, Journal of Public Economics 43 (1990) 353-374

14. E. Pels, P. Nijkamp and P. Rietveld, A note on the optimality of airline networks, Economics Letters, 69 (2000) 429-434

15. D. Starkie, Slot trading at United States airports, A report for the Director General for Transport of the Commission of the European Communities, Putnam, Hayes and Bartlett Ltd., London (1992)

16. J. Wardop, Some theoretical aspects of road traffic research, Proceedings of the Institute of Civil Engineers, 1 (1952), 325-378 


\section{Appendix $1 \quad$ Analytical expressions for local optimization}

Both regulators have an incentive to set differentiated tolls; one for its "home airline" (denoted by the subscript $i$ ), and a higher one for the visiting airline (denoted by the subscript $-i$ ). Closed-form toll levels are obtained obtained by substituting the equilibrium $q$ 's as given in (10) (with differentiated tolls rather than the simple the $t$ 's) into (26) and maximizing over $t$, and read:

$$
\begin{aligned}
& t_{i}^{w, l}=\frac{\left(\alpha \lambda-c^{f}-\lambda c^{q}\right) 2 \eta_{h}\left(v o t_{p} \lambda+v o t_{l}\right)}{5 \beta \lambda^{2}+14 \eta\left(\lambda v o t_{p}+v o t_{l}\right)} \\
& t_{-i}^{w, l}=2 \frac{\left(\alpha \lambda-c^{f}-\lambda c^{q}\right)\left[3 \eta_{h}\left(v_{p o t} \lambda+v o t_{l}\right)+\lambda^{2} \beta\right]}{5 \beta \lambda^{2}+14 \eta\left(\lambda v o t_{p}+v o t_{l}\right)}
\end{aligned}
$$

Likewise, the following undifferentiated local toll is obtained:

$$
t^{w, l}=\frac{\left(\alpha \lambda-c^{f}-\lambda c^{q}\right)\left[4 \eta_{h}\left(\operatorname{vot}_{p} \lambda+v o t_{l}\right)+\lambda^{2} \beta\right]}{5 \beta \lambda^{2}+14 \eta\left(\lambda v o t_{p}+v_{l} t_{l}\right)}
$$

